\title{
Reflections on 100 years of IAU
}

\author{
Catherine Cesarsky \\ Laboratoire AIM/Département d'astrophysique, CEA/Irfu, Université Paris Saclay, France \\ email: catherine.cesarsky@cea.fr
}

\begin{abstract}
One hundred years ago, the International Astronomical Union was created, one of the very first Unions dedicated to the advancement of a discipline and the promotion of international collaboration and exchange. In 100 years, astronomy has made huge progress, and the IAU has greatly expanded in volume and purpose. In recent years, it has become more and more active in education, astronomy for development and dissemination of astronomy to a large public.
\end{abstract}

Keywords. Astronomy, History, Union

\section{IAU history}

It will soon be 100 years since the International Astronomical Union, the IAU was created. A most interesting and enjoyable account of the first half century of IAU was written by a former IAU President, Adriaan Blaauw (Blaauw 1994), and the history of the whole first century is being put on paper by Johannes Andersen, David Baneke and Claus Madsen (Andersen et al. 2019). I here recall some of the main events.

The IAU was born at an international conference in Brussels in July 1919. Its conception immediately followed the creation of the International Research Council (IRC), the future ICSU. Astronomy was considered to be a universal science, whose advances required, more than for most disciplines, exchange between professionals all over the globe. The stated purpose of the Union was "to promote and safeguard the science of astronomy in all its aspects through international cooperation", with emphasis in the first years on facilitating the relations between astronomers of different countries carrying out joint programmes in various sub-fields. Promptly, a Convention was signed, establishing 32 "Standing Commissions", of which 16 survived until 2015.

Martin Harwit, in his beautiful book on cosmic discovery (Harwit 1981) emphasized the acceleration of the pace of discovery of astronomical phenomena in the 20th century, powered by the deployment of more and more powerful and sophisticated instrumentation on the ground and in space. The following years have been even more productive and all contemporary astronomers are conscious to be living in the golden age of their discipline. Thus, on the professional side, the first century of the IAU has been highly rewarding for all its members, making for lively and exciting meetings and collaborations, cementing ties between national communities and between individuals from all over the world.

It may seem evident that our Union should be open to all the nations of the world, irrespective of political biases and of world tensions, in other words free of politics, but that has proven impossible. In reality, it has not been easy to assemble so many nations of the globe under the IAU umbrella. The IAU was founded in the aftermath of the First World War, by countries that were all on the side of the Allies who claimed victory in 1918: Belgium, Canada, France, Greece, Japan, United Kingdom and United States of America. Rancour was still deep. Much diplomacy and hard work were required to extend the membership, but these also came with rewards. In the words of Jan Oort, former 
Table 1. Chronology for IAU Member Countries

\begin{tabular}{|c|c|c|c|c|}
\hline 1920 Belgium & 1927 Argentina & 1961 Turkey & 1992 Russian & 2006 Lebanon \\
\hline 1920 Canada & & & Federation & 2006 Mongolia \\
\hline 1920 France & 1932 Vatican & 1964 Germany split: & 1992 Estonia & 2006 Thailand \\
\hline 1920 Greece & & $B R D / G D R$ & & \\
\hline 1920 Japan & 1935 China & 1964 India & 1993 Czech Republic & 2009 Costa Rica \\
\hline 1920 United Kingdom & 1935 Soviet Union & 1964,1979 Indonesia & 1993 Slovakia & 2009 Honduras \\
\hline 1920 United States of & 1935 Yugoslavia & 1964 New Zealand & 1993 Lithuania & 2009 Panama \\
\hline \multirow[t]{2}{*}{ America } & & 1964 DPR Korea & 1993 Tajikistan & 2009 Viet Nam \\
\hline & 1939 Australia & & 1993 Ukraine & \\
\hline 1921 Italy & & $1969 \operatorname{Iran}$ (suspended) & & 2012 Ethiopia \\
\hline \multirow[t]{2}{*}{1921 Mexico } & 1947 Chile & & 1994 Armenia & 2012 Kazakhstan \\
\hline & 1947 Hungary & 1970 Uruguay & 1994 Georgia & 2012 DPR Korea \\
\hline 1922, 1961 Brazil & 1947 Ireland & & (suspended) & \\
\hline 1922 Czecho-Slovakia & & 1973 Korea & 1994 Croatia & 2015 Columbia \\
\hline 1922 Denmark & 1948 Finland & & & \\
\hline 1922 Netherlands & & 1982 China Nanjing & 1996 Latvia & 2018 Nigeria \\
\hline 1922 Norway & 1951 Germany & 1982 China Taipeh & & (rejoining) \\
\hline 1922 Poland & & & 1997 Central & 2018 Morocco \\
\hline 1922 Romania & 1953 Venezuela & 1988 Iceland & American Assembly of & (rejoining) \\
\hline 1922,1938 South & & 1988 Malaysia & Astronomers & 2018 Algeria \\
\hline Africa & 1954 Israel & 1988,2001 Morocco & & 2018 Jordan \\
\hline 1922 Spain & & (suspended) & 1998 Bolivia & 2018 United Arab \\
\hline 1923 Switzerland & 1955 Austria & 1988 Peru & (suspended) & Emirates \\
\hline & & (suspended) & & 2018 Mozambique \\
\hline 1924 Portugal & 1957 Bulgaria & 1988 Saudi Arabia & 2001 Philippines & 2018 Madagascar \\
\hline & & (suspended) & & 2018 Slovenia \\
\hline 1925 Egypt & 1959 Taiwan & & 2003 Nigeria & 2018 Syria \\
\hline 1925 Sweden & & & 2003 Serbia & \\
\hline
\end{tabular}

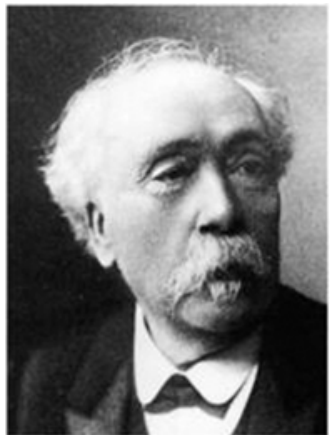

B. Baillaud, 1919-1922

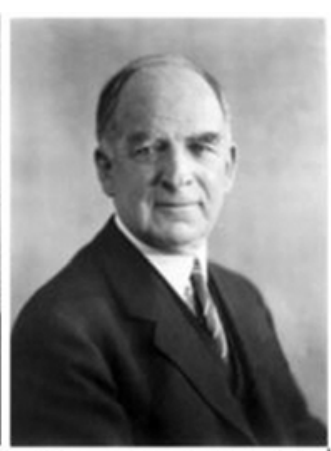

W. Campbell, 1922-1925

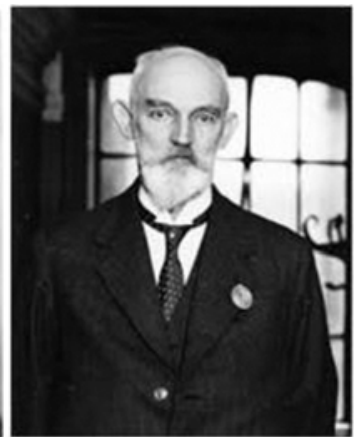

W. de Sitter, 1925-1928

Figure 1. The first three IAU Presidents: B. Baillaud, 1919-1922; W. Campbell, 1922-1925; W. de Sitter, 1925-1928.

IAU General Secretary (GS) and later President, at the 50th anniversary of the IAU: the IAU has been "building up international understanding and fertile contact between countries where sometimes relations outside astronomy were extremely poor. Politicians have rightly envied us for the natural ties between peoples we have been able to establish and conserve." (quoted in Blaauw 1994).

Table 1 gives the chronology of IAU membership, the dates at which countries joined and sometimes left and re-entered the IAU. It is clearly a reflection of the history of international relations, intertwined with the pace of development of different regions of the world. By the second General Assembly, in 1925, the Union comprised 22 member states and 248 individual members. In 2016, the IAU counted 73 member states and 10308 individual members.

The first IAU President (1919-1922) was Benjamin Baillaud (Fig. 1), from the Observatoire de Paris, a specialist in mathematics and celestial mechanics. He was the founder of the Bureau International de l'Heure, which was a subsidiary of the IAU at the time. He was followed (1922-1925) by William Wallace Campbell, from the 


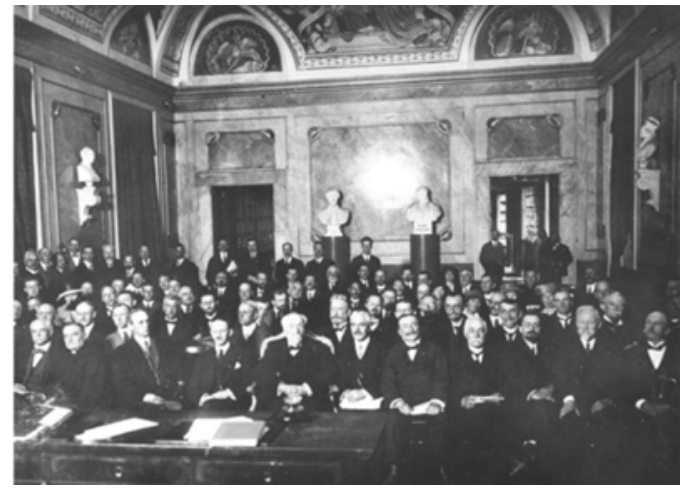

Figure 2. Pictures from some General Assemblies. First GA, Rome, 1922. Note the first President, B. Baillaud, and the first General Secretary, A. Fowler.

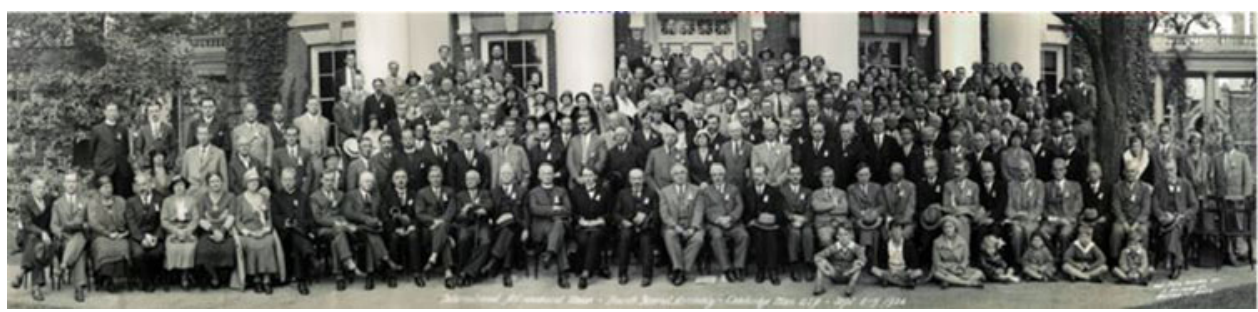

Figure 3. Pictures from some General Assemblies. Fourth GA, Cambridge, USA, 1932. On this picture appear not only the incumbent President, F. Dyson, but several future ones: B. Linblad, A. Danjon, J. Oort, F. Schlesinger and A. Eddington. Also, not only the incumbent acting GS, F. Stratton, but also J. Oort and W. Adams (from Blaauw, 1994).

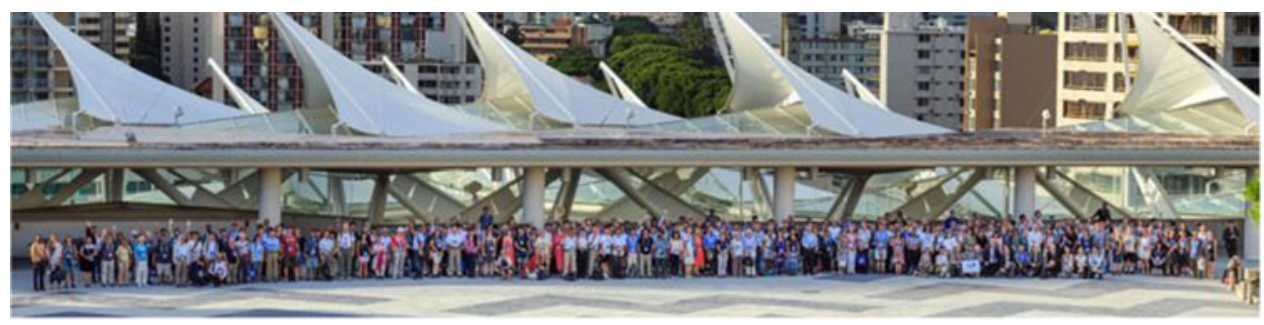

Figure 4. Pictures from some General Assemblies. IAU GA in Hawaii, 2015.

Lick Observatory. Willem de Sitter, Director of the Leyden Observatory, was the third President (1925-1928).

\section{IAU General Assemblies, other meetings and Science}

\subsection{GA birth and growth, high ranking political figures}

From the start it was decided to hold a General Assembly every three years. The first General Assembly took place in Rome in May 1922, with 83 participants. In Figs. 2-4, pictures taken at three General Assemblies are displayed: the first one, Rome; the fourth one, in Cambridge, Massachusetts, 1932, with 198 astronomers and guests, and the most recent one in Hawaii in 2015, with 3000 attendees.

General Assemblies are an opportunity to raise the profile of basic science in general and astronomy in particular in the host country. On several occasions, high ranking authorities have honoured our Assemblies. In New Dehli, in 1985, with Robert Hanbury Brown 


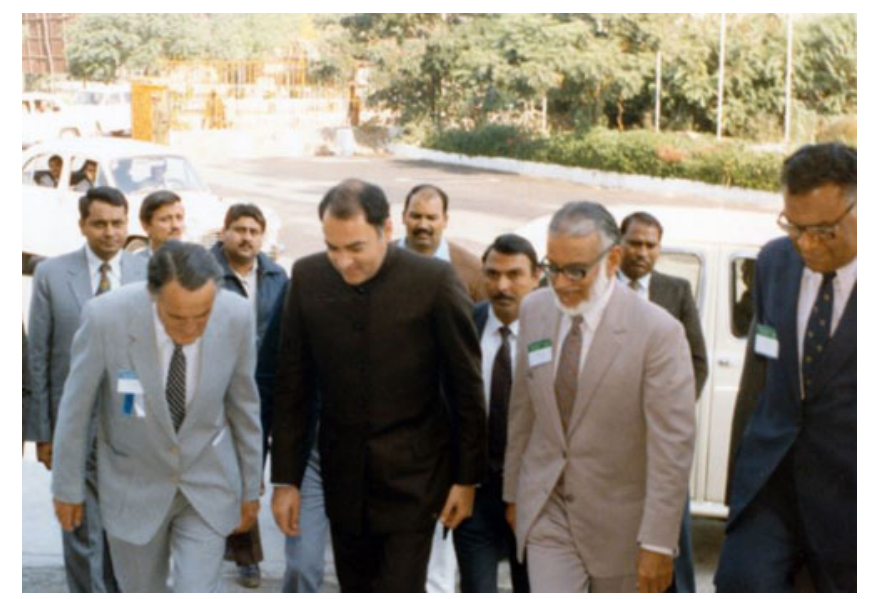

Figure 5. High-ranking authorities honour the IAU's General Assemblies; a) Prime Minister Rajiv Gandhi, IAU President Hanbury Brown; IAU GA New Delhi, India, 1985.

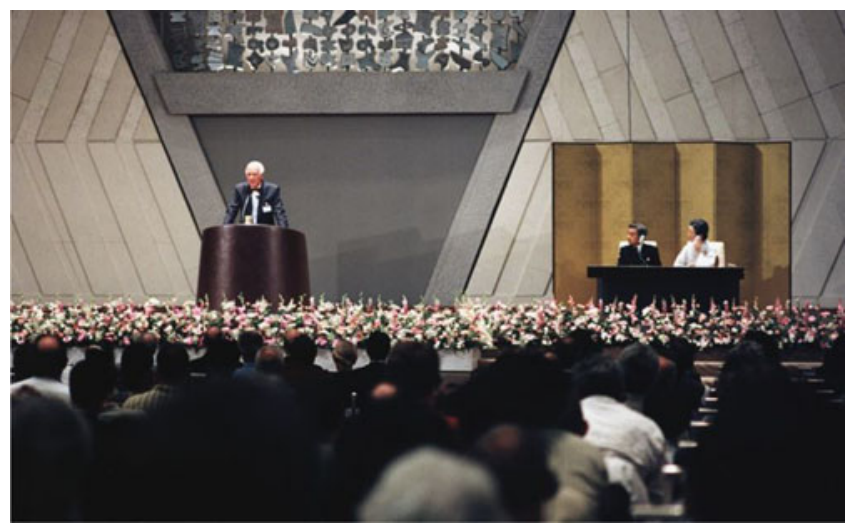

Figure 6. IAU President Lodewijk Woltjer opens the 1997 GA in Kyoto in the presence of Japan's imperial couple.

as IAU president, Prime Minister Rajiv Gandhi gave an inspiring speech on the value of science to society. In 1997, in Kyoto, with Lo Woltjer as IAU President, the emperor Akihito gave an opening speech. He talked about the recent development of astronomy, and the work of Harumi Shibukawa, Japan's first professional astronomer, who executed Japan's first original almanac based on his observations. Emperor Akihito and empress Michiko then joined the afternoon reception and talked with many astronomers individually. In 2012 in Beijing, with Bob Williams as IAU President, Xi Jinping, Vice-President of the People's Republic of China, received a group of us to discuss about the IAU, astronomy and scientific exchange. He then addressed the audience of the opening event, exposing his views on the importance of astronomy and on international cooperation in science (Figs. 5-7). These were unforgettable occasions for all astronomers present.

\subsection{Science at the $I A U$}

The IAU was created primarily to provide opportunities for world astronomers to plan and execute research projects requiring participation of several countries, but soon GAs started encompassing lectures from top scientists where recent advances could be presented. Still, the emphasis of the Union was less on science than on organizational 


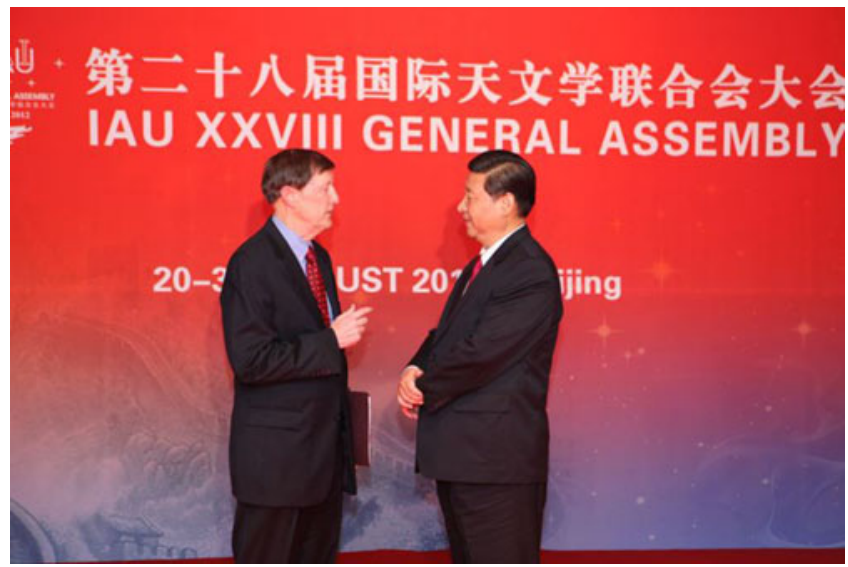

Figure 7. Robert Williams (IAU President in 2009-2012) and Xi Jinping (Vice-President of the People's Republic of China at the time) during the IAU General Assembly 2012 held in Beijing, China.

endeavours. By 1950, complaints arose: astronomers asked the IAU to enhance opportunities for in-depth discussions on selected topics, and Symposia and Joint Discussions (now called Focus Meetings) were initiated in 1952. In reality, the first Symposium, Problems of Cosmical Aerodynamics, took place in Paris in 1949 and can be numbered Symposium 0. The official No. 1 Symposium was on Coordination of galactic research, in Groningen, in 1953. Of course, since then, Symposia, and for a while Colloquia, have become an essential trademark of the IAU, perhaps the most visible for the international community of astronomers. There are now about nine IAU Symposia per year. This one is number 349, and practically every sub-discipline has been covered and has given rise to an up-to-date volume on the theme selected.

In 1954, Invited Discourses were introduced into the GAs, meant for the public. They remain today as an opportunity to honour some of our members, and to bring overviews of exciting results to all attendees, not only astronomers but also interested spouses and accompanying persons.

By the end of the 20th century, IAU astronomers started complaining again, arguing that while Symposia were interesting, GAs were loaded by business meetings of all kinds and not enough scientific exchanges took place. As a response, in 1997, at The Hague, the decision was taken to incorporate six Symposia in each GA, in addition to the Joint Discussions. This has made GAs much more attractive, and the number of attendees rose. However, GAs should be an opportunity for all astronomers not only to catch up in their specific subfield, but also to be informed at the best possible level about advances in other fields of the discipline. Thus, at my request, since the GA in Rio de Janeiro in 2009, each GA Symposium has been assigned a plenary talk in the morning. These talks attract many in the audience and are very useful to prevent a split of the astronomical community into small groups of specialists.

\subsection{Location of GAs}

The IAU was born in Europe, and naturally 17 of the 30 GAs to date have been held there (Fig. 8). North America swiftly entered into the game, in 1932, and three GAs were hosted in the continental USA plus one in Hawaii, and one in Canada. Russia hosted the 1958 GA. Two GAs took place in Sydney, Australia. Three GAs have been held in Asia, starting with India in 1985, and the 2021 one will be in Korea. There have been GAs in 


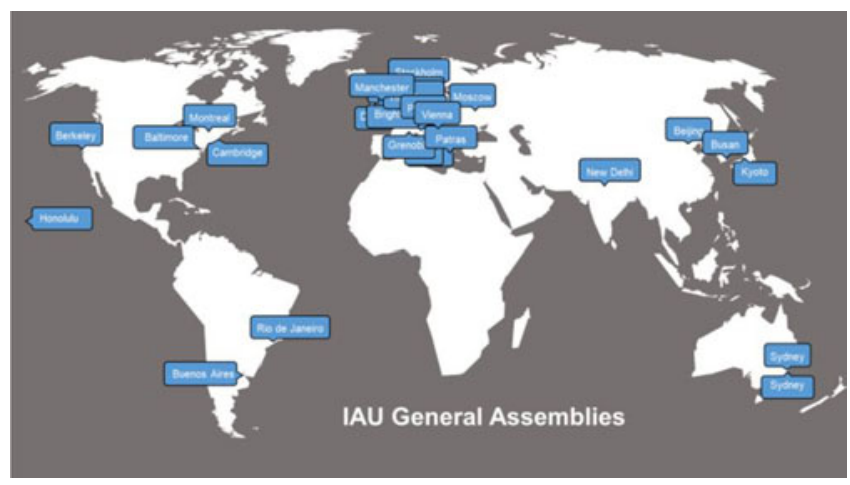

Figure 8. Location of GAs from 1922 to 2018.

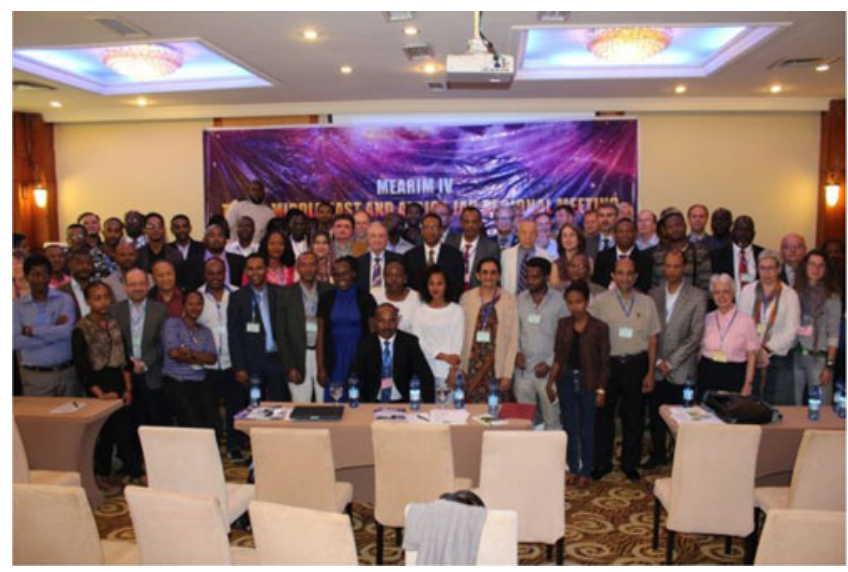

Figure 9. MEARIM4 in Ethiopia.

South America on two occasions, the first one being in Argentina in 1991. In 2024, for the first time, the GA will go to Africa, a well-deserved tribute to the fast progress of astronomy in South Africa and other African countries.

\subsection{Regional Meetings}

In addition to the General Assemblies, the IAU fosters encounters of astronomers at the Regional level. These are the Regional Meetings, which also take place every three years. They were started in Europe, the 12th and last was in 1990. They were stopped because it was then considered that there was already a sufficient number of astronomy meetings in Europe. But since 1992 they have resumed (JENAM, and then EWASS) and their importance keeps growing, under the wing of the European Astronomical Society created in 1990. In North America, there are bi-annual AAS meetings, fulfilling this role. In other areas of the world, IAU Regional Meetings exist and keep gaining in attendance and scientific level. They are very useful to let neighbouring communities get to know each other better, and foster collaborations and projects (see the contribution by Norio Kaifu, in this volume). Latin America had its 15th LARIM (Latin America Regional IAU Meeting) in Colombia in 2016, the Asia and Pacific region its 13th APRIM in Taipei in 2017. In 2008 I introduced the Middle East and Africa Regional Meetings. The first took place in Cairo, Egypt. MEARIM4 took place in Ethiopia in 2017 (Fig. 9). 

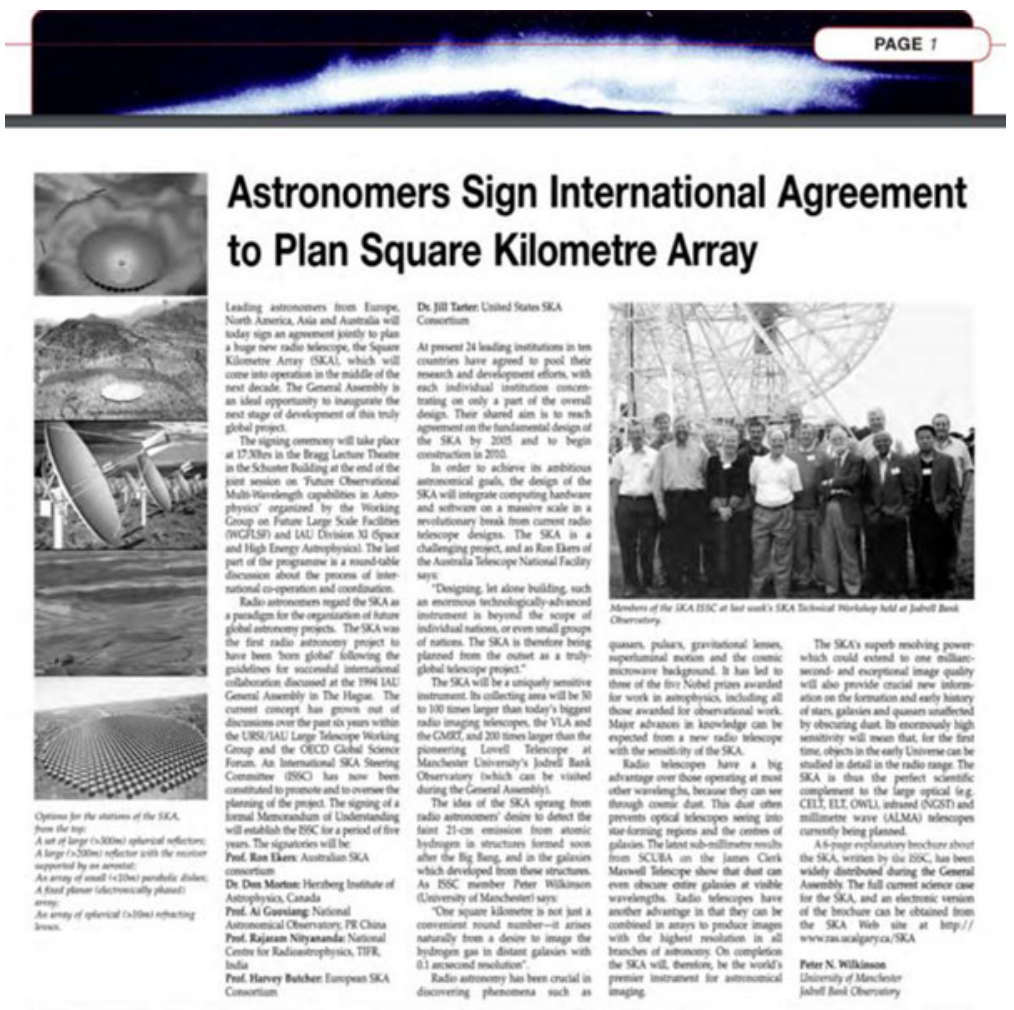

Figure 10. SKA Agreement in IAU newspaper, Manchester, 2000.

\subsection{Large facilities}

In 1946, Harlow Shapley, with the support of Polish astronomers, introduced the idea of a Commission on International Observatories. The aim was for the IAU to foster conception and construction of World observatories, open to all countries, with financial help from UNESCO. Commission 39 was created for this purpose and existed from 1948 to 1955. The IAU International Observatories dreamt by Harlow Shapley never happened, but at the 1994 GA in The Hague, a Working Group on Global Coordination of Ground and Space Astrophysics, reporting to the Executive Committee, was created and has continued ever since. In 2018, at the Vienna GA, it held a Focus meeting on Coordination, which led to useful exchanges between facility and instrument builders from all over the world. The closest IAU has been in fostering a World Observatory was at the Manchester GA in 2000, where the international agreement to plan a very large international radioastronomy project, the Square Kilometre Array, was signed under the auspices of the IAU (Fig. 10).

\section{IAU Structures, old and new}

As with all living organisms, the IAU went through growing pains, including periods of dissatisfaction of members and/or officers. These induced healthy changes, which more often than not took several years to be implemented. Restructuring of the IAU has been a recurrent theme all along.

In 1960, protests and discussions led to a higher autonomy for the Commissions. In 1965, the General Secretary, D. Sadler, proposed to have the Commissions regrouped into 


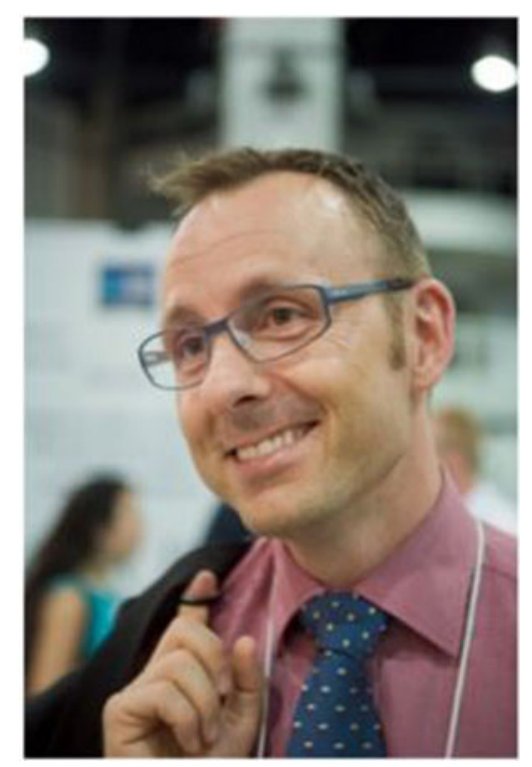

Figure 11. IAU Press Officer, Lars Lindberg Christensen.

seven or eight Sections, and later the GS L. Perek proposed regrouping the Commissions into several themes. However, this did not happen.

In 1967, GS Jean-Claude Pecker, whose wonderful account of his souvenirs of the IAU we had the privilege of hearing at this Symposium, wrote: "the moment has come to revise from top to toe the scientific and administrative functioning of the Union". This gave rise to a thorough revision of the Statutes and Bylaws. Finally, in 1997, President L. Woltjer and GS I. Appenzeller regrouped the Commissions by themes and introduced Divisions, with the intention to have the Division Chairs eventually replace the six vicepresidents of the Executive Committee. Little by little, Division Presidents took over scientific tasks from the Executive Committee, but the Executive Committee with its six vice-presidents remained for political purposes and for supervision of various actions of the Union. A new list of Divisions, Commissions and Working Groups was drawn under President N. Kaifu and GS T. Montmerle in 2015, in close relation with the evolution of astronomical research.

In the meantime, in 2009-2012, President R. Williams and GS I. Corbett updated the Statutes and Bylaws and Working Rules and added greatly to democracy in the Union with the introduction of electronic votes.

\section{Outreach and the International Year of Astronomy 2009 (IYA 2009)}

\subsection{The Pluto affaire in 2006}

The IAU situation regarding outreach made a big step in the direction of professionalism when, in 2006, Lars Lindberg Christensen, from ESA and ESO at the time, accepted to become IAU Press Officer (Fig. 11).

The appointment could not have been timelier, as 2006 was the year of the IAU GA in Prague, with Ron Ekers as President, where the turmoil about the status of Pluto took place. The vote itself occurred after a discussion led by Jocelyn Bell Burnell, who was the Chair of the Resolutions Committee (Figs. 12,13). Ron Ekers in this Symposium relates the events around this decision. There was a strong reaction from the media, the 


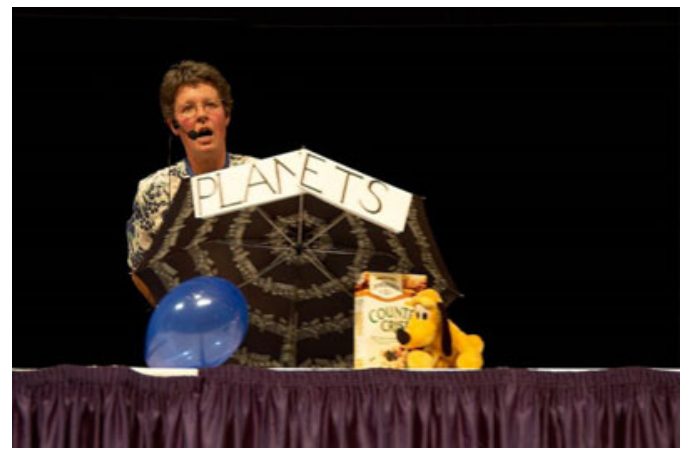

Figure 12. Jocelyn Bell Burnell, Chair of the Resolutions Committee, Prague 2006, at the time of the vote on the status of Pluto.

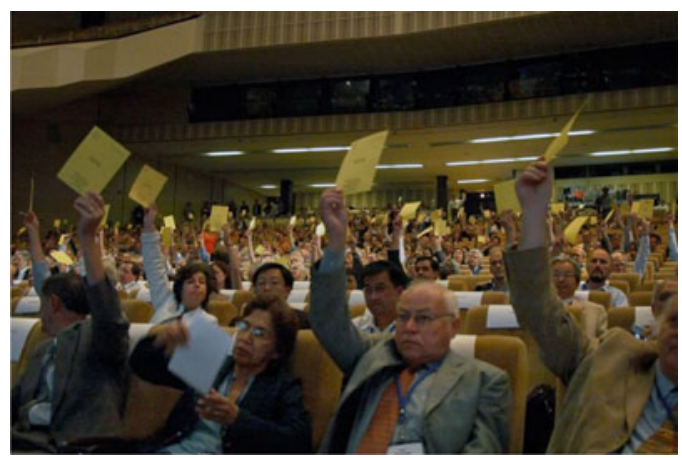

Figure 13. Voting at the IAU GA in Prague, 2006.

press room was constantly full of reporters (Fig. 14). Here I just want to comment on its impact on the IAU image to the outside world. I can do it no better than by quoting Lars himself, given that I fully agree with his reflections (Christensen 2007):

"A colourful engaging science story with human flair! The Pluto affair was the biggest story of any IAU GA, and possibly in general, in the last year. The new definition of a planet has provoked strong reactions that still persist. The positive effects outweigh the negative by far. A large fraction of the demographic segment of people inattentive to science was exposed to science! People even offer their opinion. It is the first time in many years (to my knowledge) that any scientific topic has penetrated so deeply into the public conscience! E.g. the large number of cartoon jokes/caricatures. The public today has a much better knowledge of the IAU and its mission and some better idea of the wonders of the Solar System."

With the Pluto affair, the IAU broke anonymity once and for all in the eyes of the public. People not only learnt that the IAU existed, but also that they could have their own opinion on cosmic phenomena. In total, I believe that the Pluto affair paved the way for the success of IYA 2009.

\subsection{International Year of Astronomy 2009 (IYA2009)}

We owe to Franco Pacini, the IAU President from 2000 to 2003, the idea for the International Year of Astronomy. In 2001, he discussed with some of us in the Executive Committee the idea of having a celebration for the 400th anniversary of the first time 


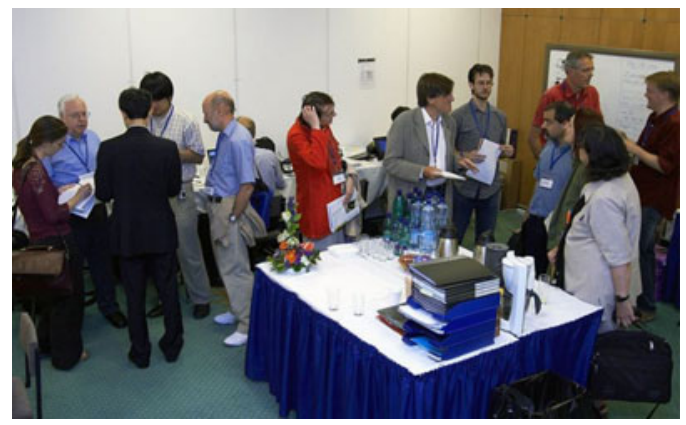

Figure 14. Busy press room over Pluto, Prague, 2006.
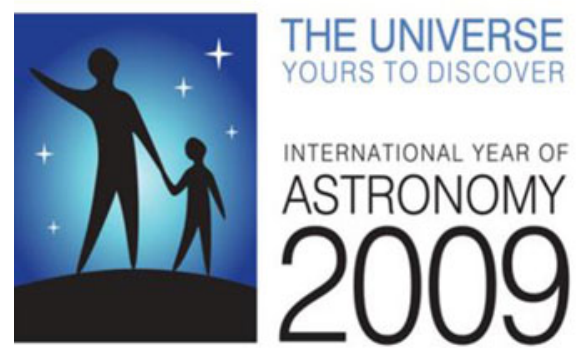

to help the citizens of the world rediscover their place in the Universe through the day-and night-time sky, and thereby engage a personal sense of wonder and discovery

Figure 15. Logo and motto of IYA 2009.

Galileo looked through a telescope. We were all enthusiastic, as was the IAU attendance at the GA in 2003, which voted a resolution calling for the preparation of IYA 2009. A first Working Group was set up, chaired by Franco Pacini himself. It was then decided that the aim of IYA2009 would not be to launch or follow international astronomy programmes, but to dedicate the year to the public. The vision was defined as: "The vision of the International Year of Astronomy 2009 is to help people rediscover their place in the Universe through the sky, and thereby engage a personal sense of wonder and discovery. Everyone should realise the impact of astronomy and other fundamental sciences on our daily lives and understand how scientific knowledge can contribute to a more equitable and peaceful society".

In 2005, the endorsement of UNESCO as a partner in the Year was secured (UNESCO 2005). In 2006, we put in place a second Working Group, which, as the new IAU President, I chaired, with Lars Lindberg Christensen as Secretary. Our first task was to define the goals and objectives of IYA 2009:

(a) Increase the scientific awareness.

(b) Promote widespread access to the universal knowledge of fundamental science.

(c) Empower astronomical communities in developing countries.

(d) Support and improve formal and informal science education.

(e) Provide a modern image of science and scientists.

(f) Facilitate new, and strengthen existing, networks.

(g) Improve the gender-balanced representation of scientists.

(h) Facilitate the preservation and protection of the world's cultural and natural heritage of dark skies in places such as urban oases, national parks and astronomical sites.

Next, we designed the logo and motto of the year (Fig. 15) 


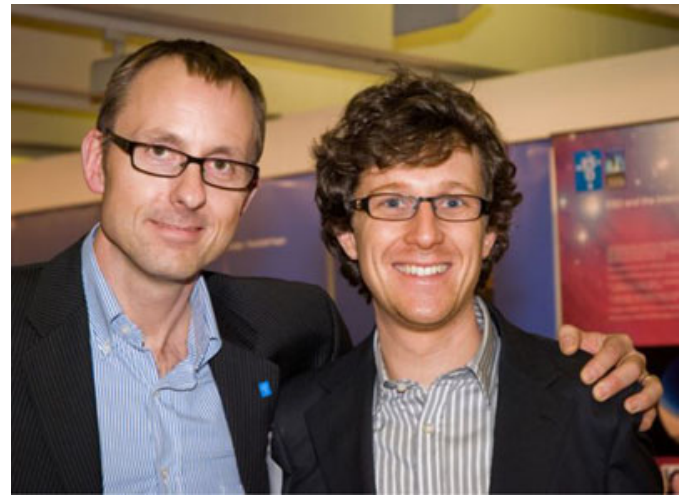

Figure 16. The backbone of IYA2009, Lars Lindberg Christensen, IYA2009 Secretariat Manager and Pedro Russo, IYA2009 coordinator.

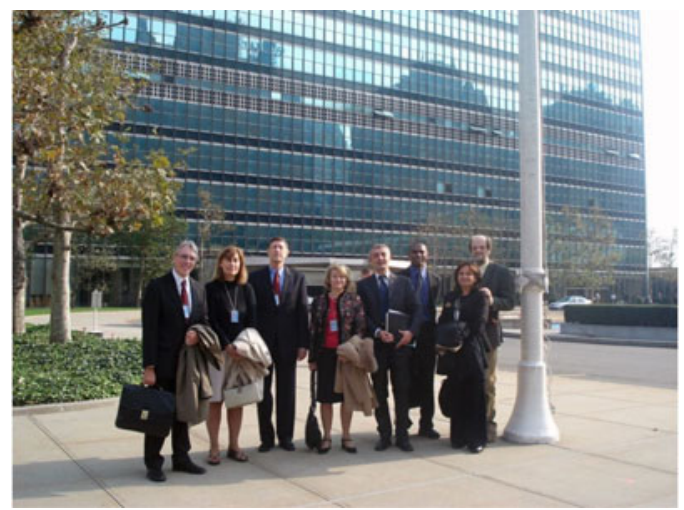

Figure 17. Obtaining the approval of United Nations for IYA2009; The official IAU delegation outside the United Nations Headquarters in 2007, from left to right: Claus Madsen (ESO), Beatriz Barbuy (IAU Vice-President), Robert Williams (IAU President Elect), Catherine Cesarsky (IAU President), Luigi de Chiara (Italian UN Mission), Kevindran Govender (SALT), Nella Le Moli (INAF) and Leopoldo Benacchio (INAF).

In 2007, an IYA2009 Secretariat was set up, hosted at ESO in Garching and managed by Lars Lindberg Christensen. Pedro Russo was hired as IYA 2009 Coordinator (Fig. 16). In 2008, Mariana Barrosa joined in to assist him, and Lee Pullen came in as staff writer, while Lars Holm Nielsen and Raquel Shida (ESO ePOD) managed the web presence.

The next hurdle was to obtain the endorsement of the United Nations (UN) for IYA2009. Italy was the front-line country, seconded by Japan. Thanks to the diplomatic skills of Claus Madsen and Enikö Patkos from ESO, and the Italian UN delegation, we obtained permission to present our request at the UN Headquarters in New York (Figs. 17,18). Our presentation was well attended, and in the same evening the UN voted unanimously in favour of declaring 2009 the International Year of Astronomy (United Nations 2007).

The IYA2009 secretariat had established a website opened to all participants. Every country designated a "single point of contact" (SPoC) most often an astronomer, sometimes an amateur astronomer, heading a national node, involving his/her country in the 12 Cornerstone projects and some of the 16 Global Projects, and creating national events. In the end, IYA2009 was the largest network ever in Science. The stakeholders were 149 countries, many of them not IAU members, 40 international organisations 


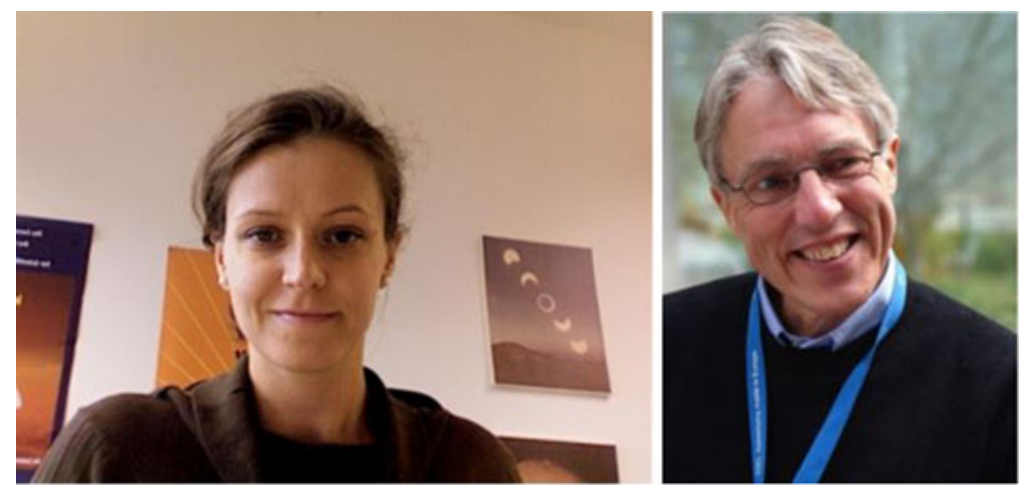

Figure 18. Enikö Patkos and Claus Madsen.
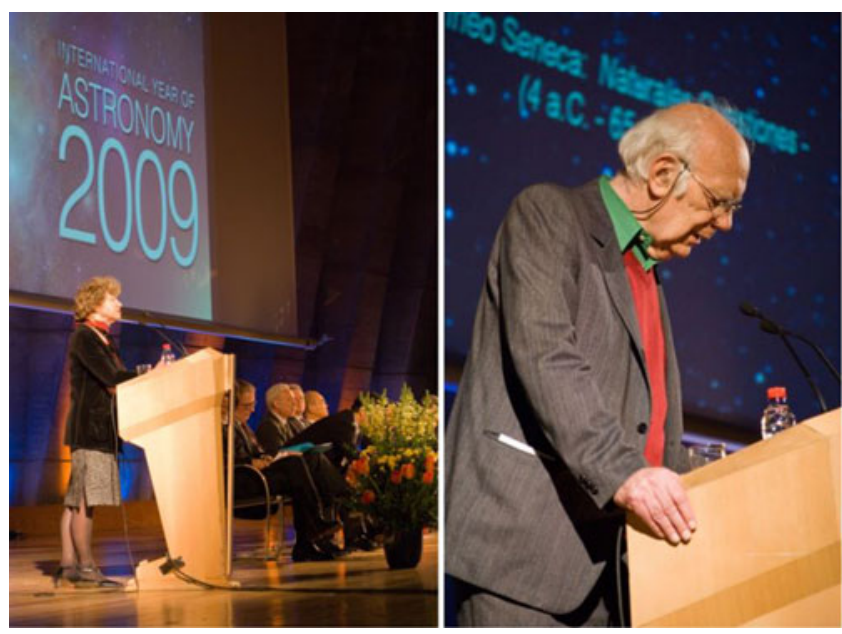

Figure 19. Images from IYA2009 Opening Ceremony, UNESCO, Paris, January 16, 2009; Catherine Cesarsky (left), Franco Pacini (right).

and 28 global projects. At the end of the Year celebrations, the website had been visited more than 25000000 times by more than 600000 unique visitors. After a huge amount of preparation, the momentous day of the Opening Ceremony arrived, hosted by UNESCO, in Paris, on January 162009 (Figs. 19-22). It featured a number of formal speeches and a two-day science colloquium. There were hundreds of attendees, including members of royal families, government ministers, Nobel Prize winners and other distinguished scientists, industrialists and young astronomers from all over the world.

A very large number of events took place, on an international as well as a national scale. They were all carefully advertised and displayed as webnews in the IYA2009 website see some examples in Fig. 23. At the end of the year, a Final Report was established (Russo \& Christensen 2010), which gathers the reports of all the Nodes. It presented in two pages "IYA2009 in numbers", e.g., three million people were involved in star parties on Galilean nights, or 180000 Galileoscopes were distributed in 105 countries to allow the public and mostly the children to relive the Galileo experience.

The closing ceremony of IYA2009 was held on January 9 and 10, 2010, at the University of Padova, which is where Galileo Galilei taught physics. The success of the year was celebrated. The activities had been completely in line with the goals and objectives set at 


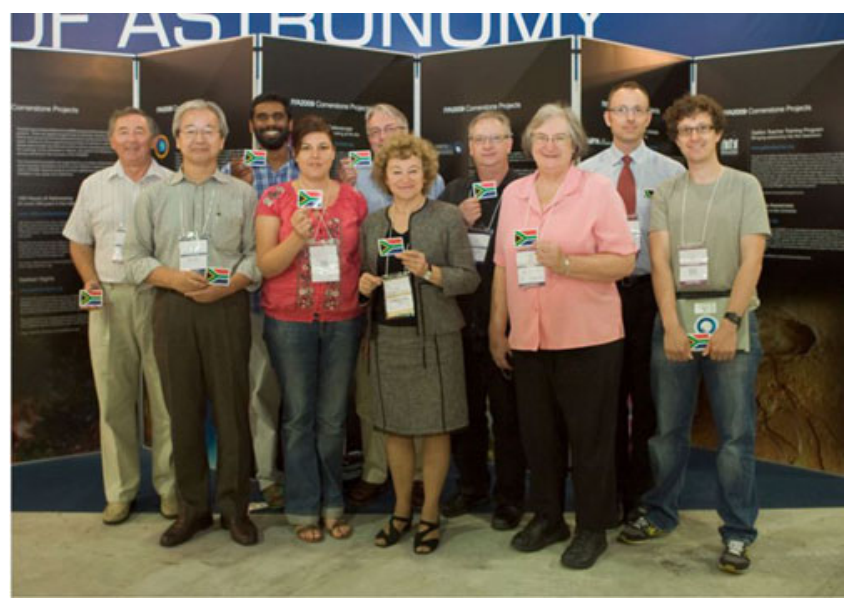

Figure 20. Members of the IAU Executive Committee Working Group IYA 2009. Left to right: Ian Robson, Norio Kaifu, Kevin Govender, Mariana Barrosa (Assistant coordinator), Claus Madsen, Catherine Cesarsky (Chair), Dennis Crabtree, Mary Kay Hemenway, Lars Lindberg Christensen (Secretary), Pedro Russo (Coordinator).

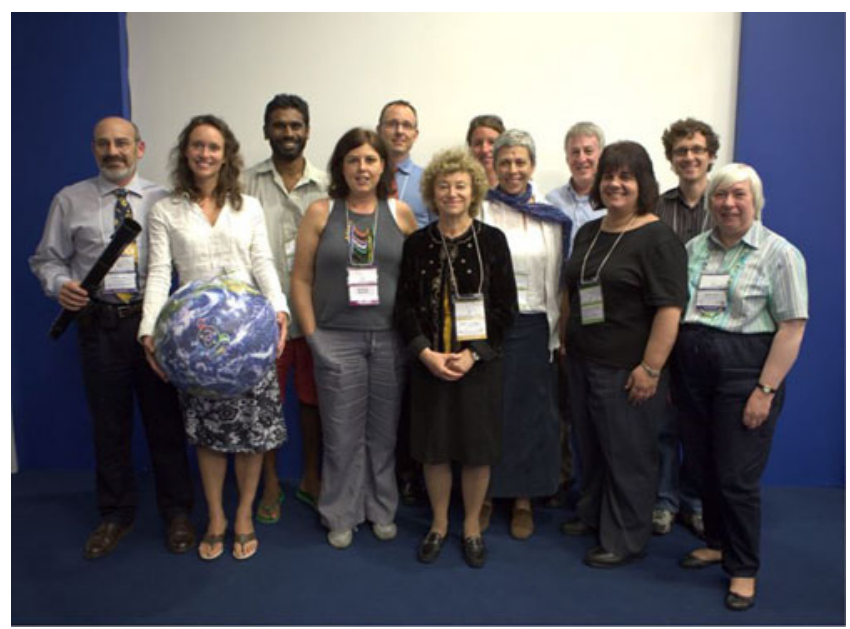

Figure 21. IYA2009 Cornerstone chairs.

the start, and the response from the public everywhere on the globe had been extremely positive. Franco Pacini was able to come, and, to our great pleasure, he expressed his satisfaction (Fig. 24).

An important theme at the Closing Ceremony was astronomy beyond 2009 and the IYA2009 legacy. Our IYA2009 Working Group remained in place till 2012, now called Beyond IYA2009, and was mainly interested in securing a future to the activities of the wonderful Year. At present, some of the Global Projects, such as teacher training, dark skies and astronomy heritage, remain active. The IAU Office of Astronomy for Development (see below) can be seen as the descendant of the Cornerstone Project: Developing Astronomy Globally. Norio Kaifu and I were very keen to perpetuate in some form the Outreach network, as well as of the contact with clubs of amateur astronomers. This is happening, thanks to the generosity of the National Astronomical Observatory of Japan, which hosts the IAU's Office for Astronomy Outreach. Sze-leung Cheung (Fig. 25) is at present the International Outreach Coordinator, leading a network of about 90 NOCs 


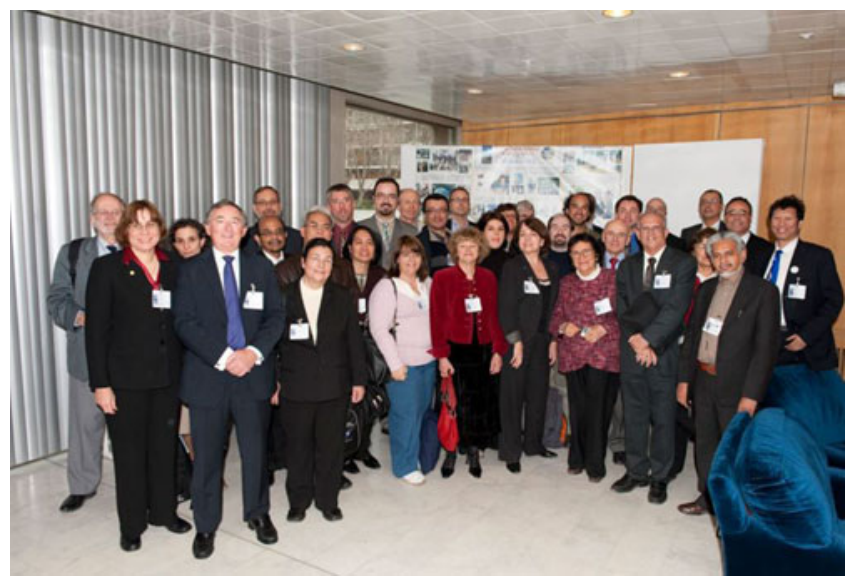

Figure 22. IYA 2009 Single Points of contact from around the world.

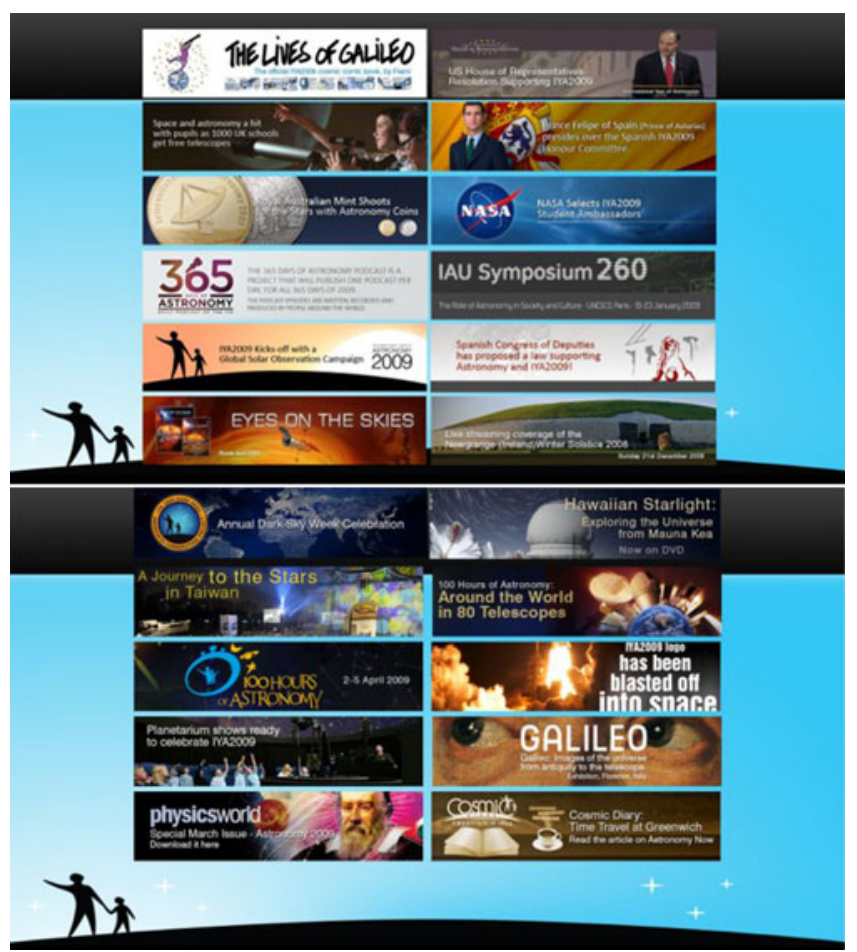

Figure 23. Some IYA2009 events, as advertised in the IYA 2009 website. See also Russo \& Christensen (2010); Russo et al. (2014).

(National Outreach Contacts or Committees), working with them just as IYA2009 worked with the SPoCs. Finally, the IAU has been a very active participant to the International Year of Light 2015.

\subsection{IAU Strategic Development Plan 2009-2019}

Meanwhile, in 2008-2009, George Miley, IAU Vice-President for Education and Development developed an IAU Strategic Plan for 2010-2020: "Astronomy for the 


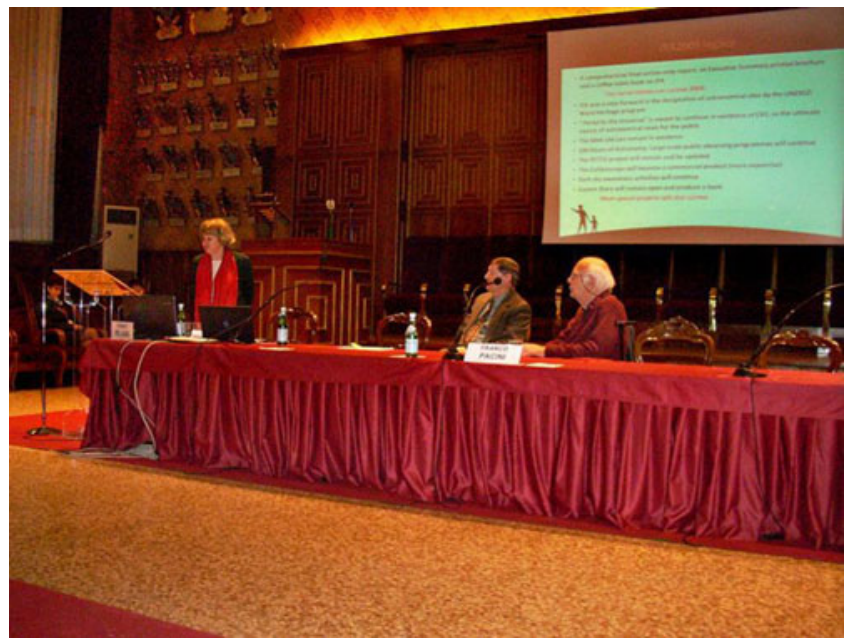

Figure 24. IYA2009 closing ceremony, Padova, 2010. Catherine Cesarsky, Chair of IYA2009 Working Group, Robert Williams, IAU President, Franco Pacini, father of IYA2009.

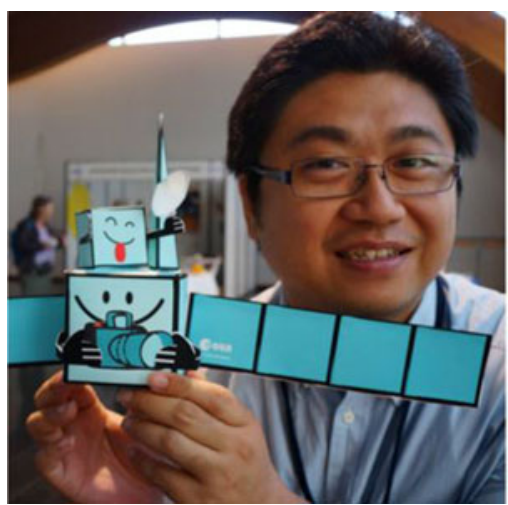

Figure 25. Sze-leung Cheung, International Outreach Coordinator, IAU Office for Astronomy Outreach.

Developing World". This plan proposed an expansion of the corresponding IYA2009 cornerstone on Development, bringing astronomical skills to developing countries not just to enhance their astronomy background, but also to help them apply these new skills to fulfil their development goals, in accordance with United Nations Sustainable Development Goals. The plan was approved by the General Assembly at the GA in Rio de Janeiro in 2009 (I was IAU President then); a new version, renamed "Astronomy for Development, building from the IYA2009" was issued in 2012 in Beijing (Miley 2012), with an update on implementation. The strategic plan called for the creation of an IAU Office of Astronomy for Development (OAD). After a lengthy international competition, the OAD was installed in Cape Town in 2011, and Kevin Govender was selected to lead it. The OAD is jointly funded by the IAU and the National Research Foundation of South Africa. As of 2017 the OAD had awarded grants to 106 projects that reached over 85 countries across the world. Ten regional offices of the OAD have been established all over the world, in Armenia, China, Colombia, Ethiopia, Jordan, Netherlands (for Europe), Nigeria, Portugal, Thailand and Zambia (Figs. 26-28). 


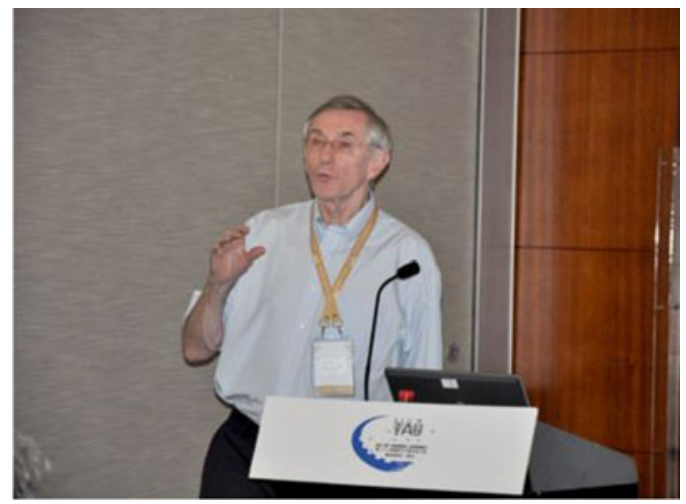

Figure 26. Astronomy for the Developing World and creation of Office for Astronomy for Development (OAD). George Miley, IAU Vice-President for Education and Development in 2008-2009.

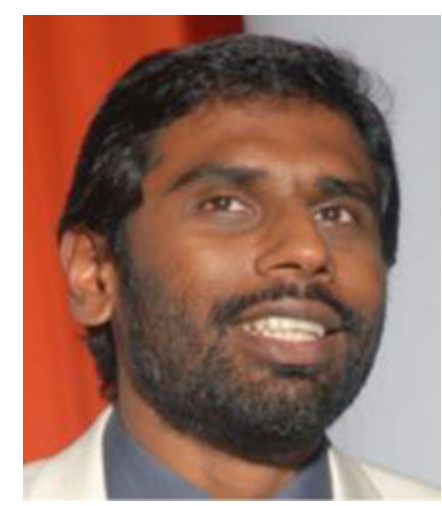

Figure 27. Kevin Govender, Director of the OAD.

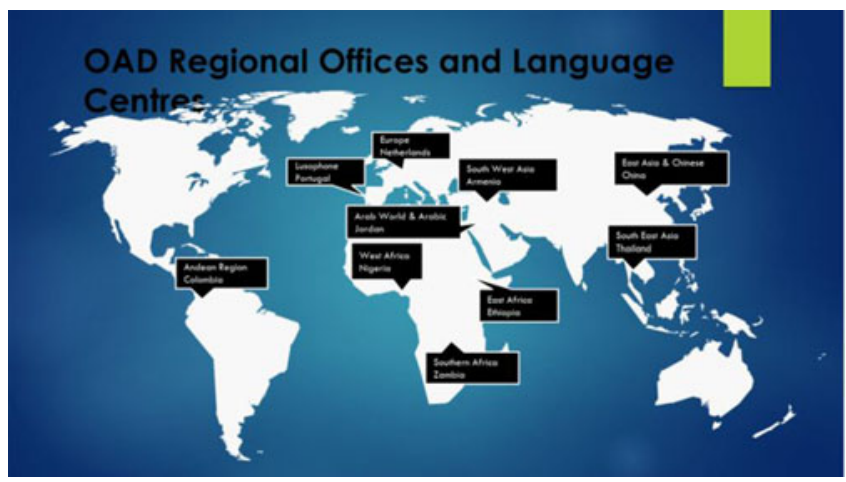

Figure 28. OAD Regional Offices and Language Centres.

\subsection{The future IAU strategic plan}

As I see with satisfaction in the new decadal plan proposed at this Assembly, a key part of the future strategy will be a clarification of the different mandates of the IAU: education, communication, astronomy training and development. Using astronomy for development will remain crucial to the IAU's mission over the next decade. 


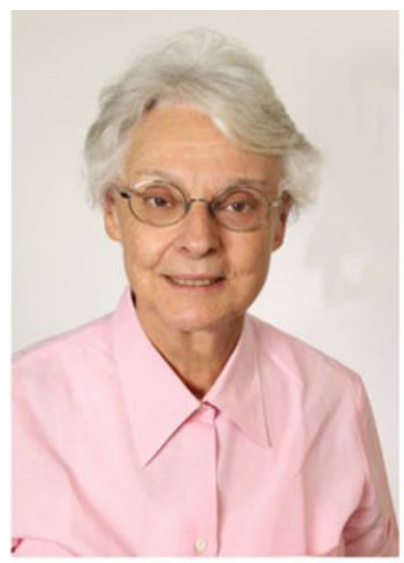

Michèlle Gerbaldi

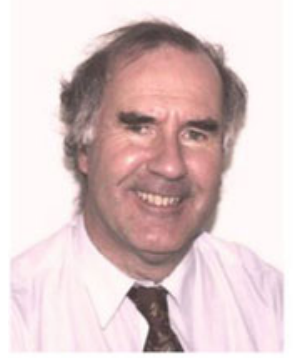

John Hearnshaw

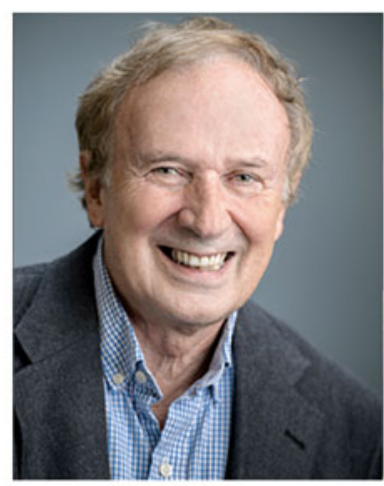

Edward Guinan

Figure 29. Michèle Gerbaldi, Edward Guinan, John Hearnshaw.

\section{IAU Educational Activities}

Since 1967, the IAU has organized all over the world International Schools for Young Astronomers (ISYA). These are three-week international postgraduate schools dealing both with theory and observations, aimed at regions where students lack opportunities to be directly exposed to the full extent of up-to-date astrophysics. I have had a chance to teach at one of these schools, and greatly admired the dedication and prowess of Michèle Gerbaldi and Edward Guinean (Fig. 29). ISYAs are very appreciated and in great demand (Fig. 30). ISYAs are now run for the IAU by a virtual Office for Young Astronomers (OYA), chaired by an IAU Vice-President, at present Xiaowei Liu. Another appreciated action towards education are the travelling astronomers, as an activity of the IAU's Program Group for the World-wide Development of Astronomy. The Chair of this Symposium, John Hearnshaw (Fig. 29) has been very active in this.

\section{The IAU and women: Officers and Executive Committees}

\subsection{Women in astronomy}

For many years, at IAU GAs, a group of disgruntled women (and some men) wished to meet and discuss the problems encountered by some women astronomers in the course of their careers. We were provided with some dark room in the centre of the deserted Convention Centre on the empty Saturday morning. The situation has greatly changed. Now we are provided with relatively plush lunches on Women in Astronomy, well attended 


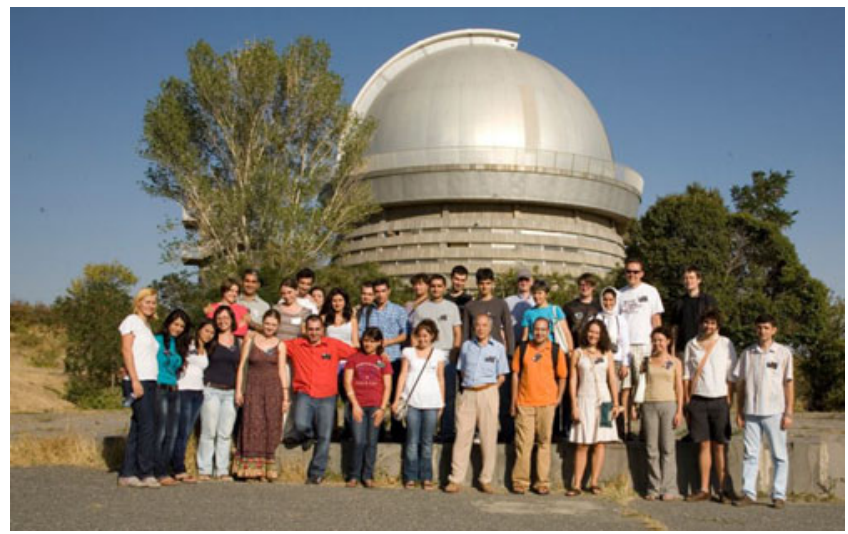

Figure 30. ISYA at Buryakan, Armenia 2010.
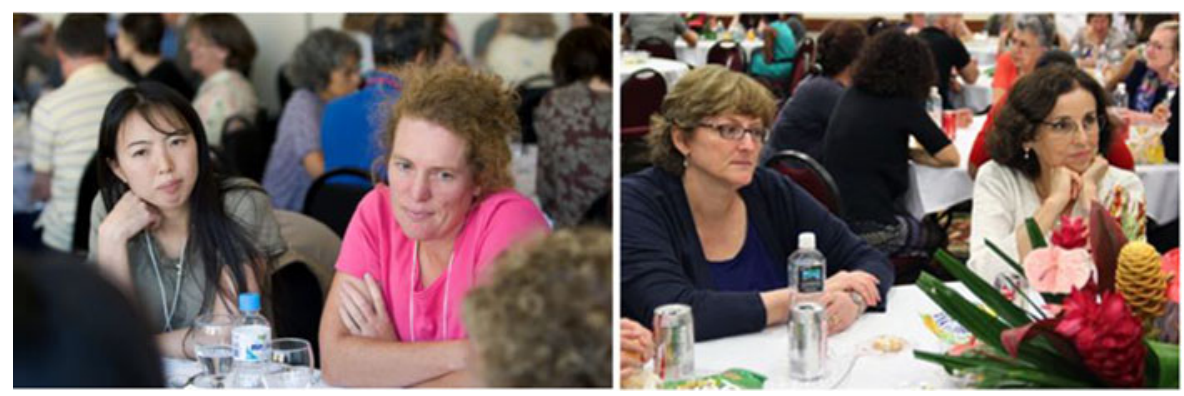

Figure 31. Women in Astronomy lunches at General Assemblies.

and with a substantial male presence, with lively presentations and conversations. I thank NSF and AAS for sponsoring these lunches (Fig. 31).

\subsection{Officers and Executives}

It is interesting to see how the profiles of Officers and Executives of the IAU have been changing in the last few years. I present here some pictures to illustrate this point (Figs. 32-36).

\section{Myself at the IAU, Presidents and General Secretaries}

I have been engaged with the IAU for many years. From 1985 to 1988, I was President of Commission 48, High Energy Astrophysics. From 1997 to 2003, I have been IAU Vice-President, and from 2006 to 2009, President and from 2009 to 2012 Past Presidentadvisor. This means I have been on the Executive Committee for 15 years!

Like Jan Oort at the IAU's 50th anniversary, I can say at the 100th anniversary that "the most important aspects have been the many personal relations and often friendships which came about through these relations...". So, I decided in the course of this paper to show you a lot of these dedicated people, most of which I have known and respected, 


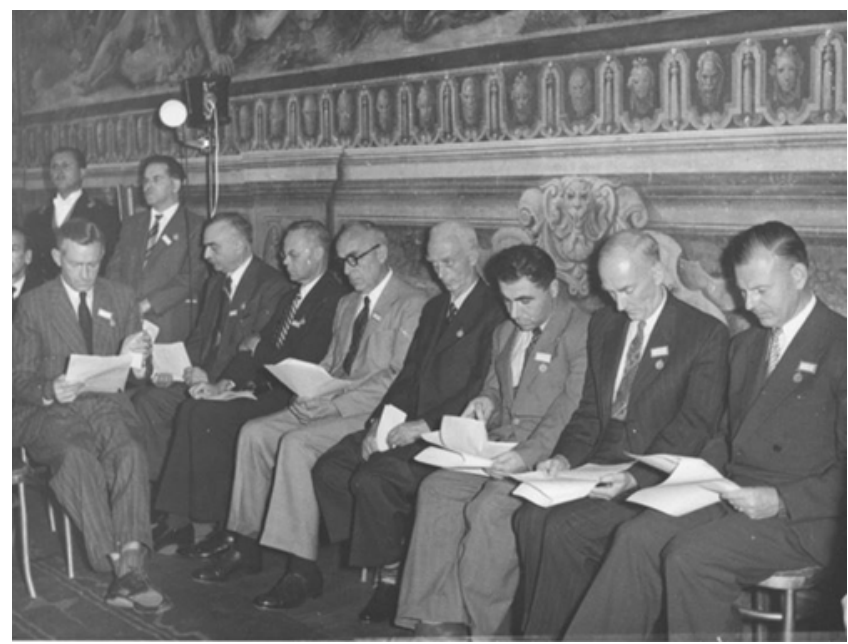

Figure 32. IAU Officers and Executives. IAU GA 1952, Rome, Executive officers. Left to Right: A. Danjon, O. Struve, H. Spencer Jones, G. Tiercy, V.A. Ambartsumian, J.H. Oort, B. Strömgren and other Executives. Danjon, Oort and Strömgren all became later Presidents of the IAU.

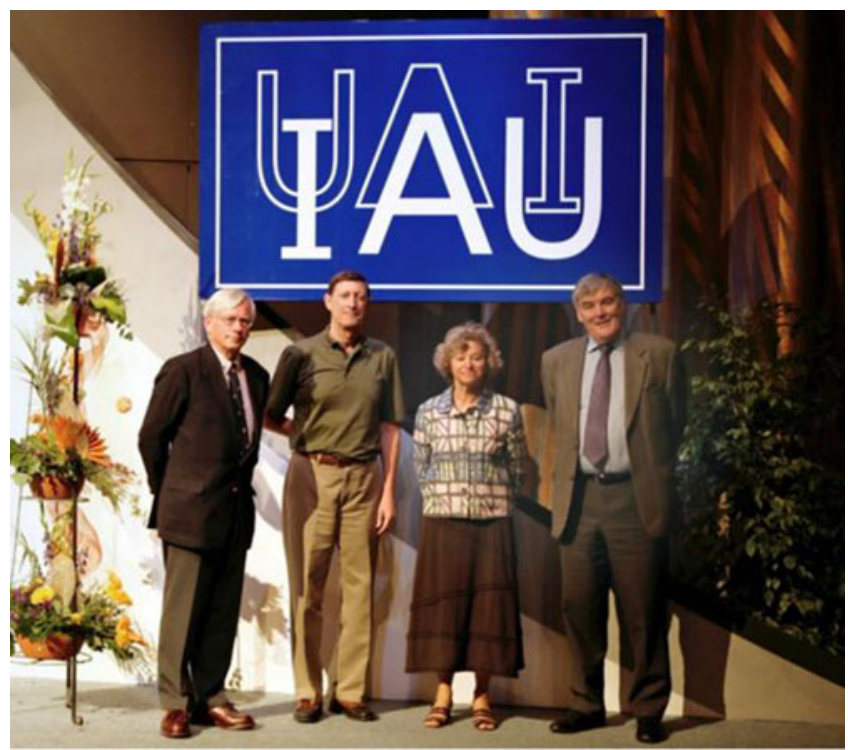

Figure 33. The new IAU Officers in 2006: K. van der Hucht, R. Williams, C. Cesarsky, I. Corbett.

many of which I have befriended. . I would like to show a few more. First, IAU Presidents since 1955 (Fig. 37).

Last but not least, I wish to highlight the General Secretaries. Selfless and dedicated, they are the backbone of the IAU. As Johannes Andersen says (Fig. 38), they are responsible for everything... This is why I wish to conclude this paper by expressing to them all my gratitude. 


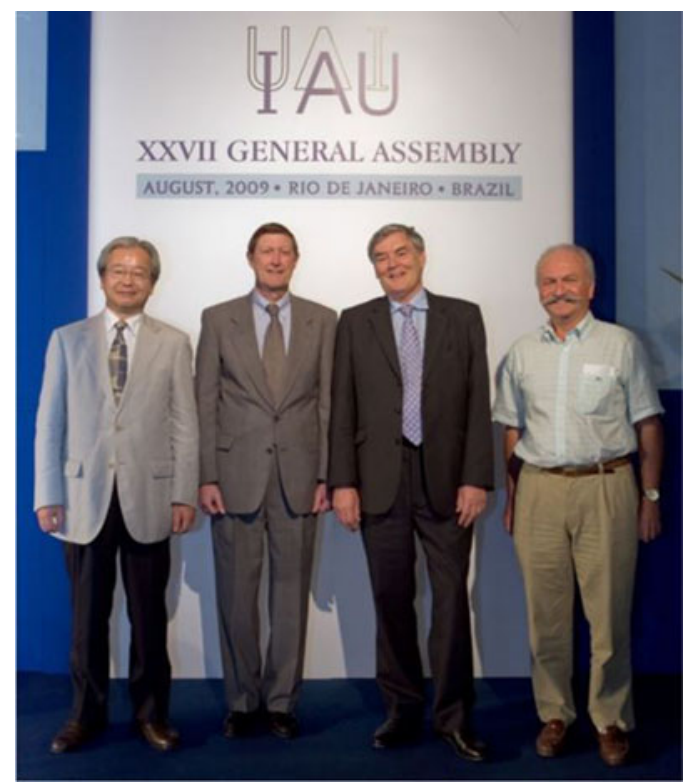

Figure 34. The new IAU Officers in 2009: N. Kaifu, R. Williams, I. Corbett, T. Montmerle.

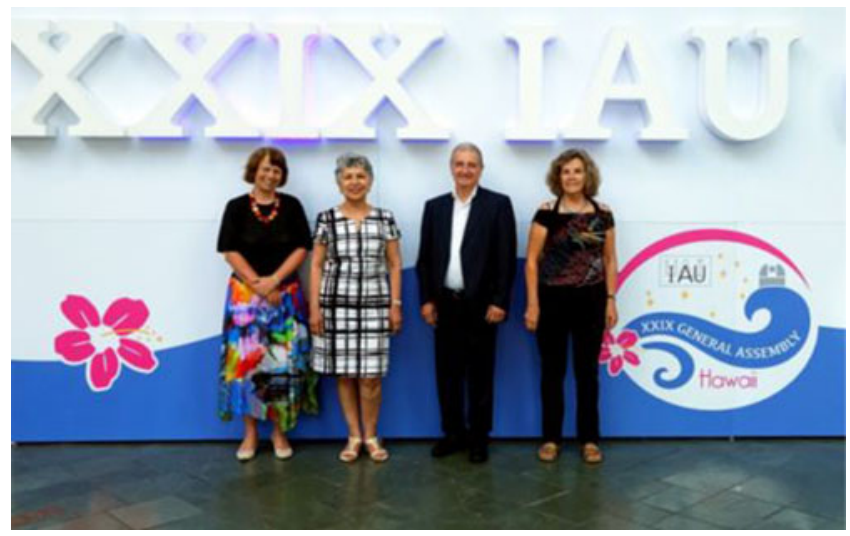

Figure 35. The new IAU Officers in 2015: E. van Dishoeck, S. Torres, P. Benvenuti, T. Lago.

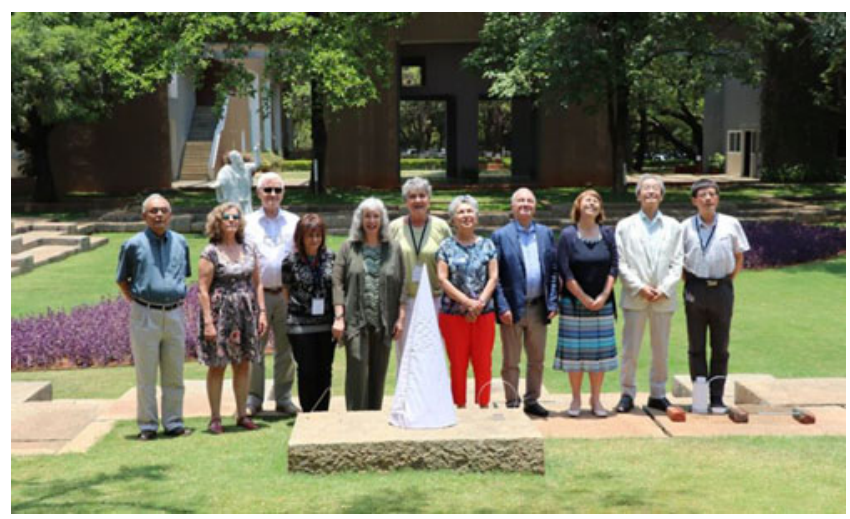

Figure 36. Executive committee 2017. 


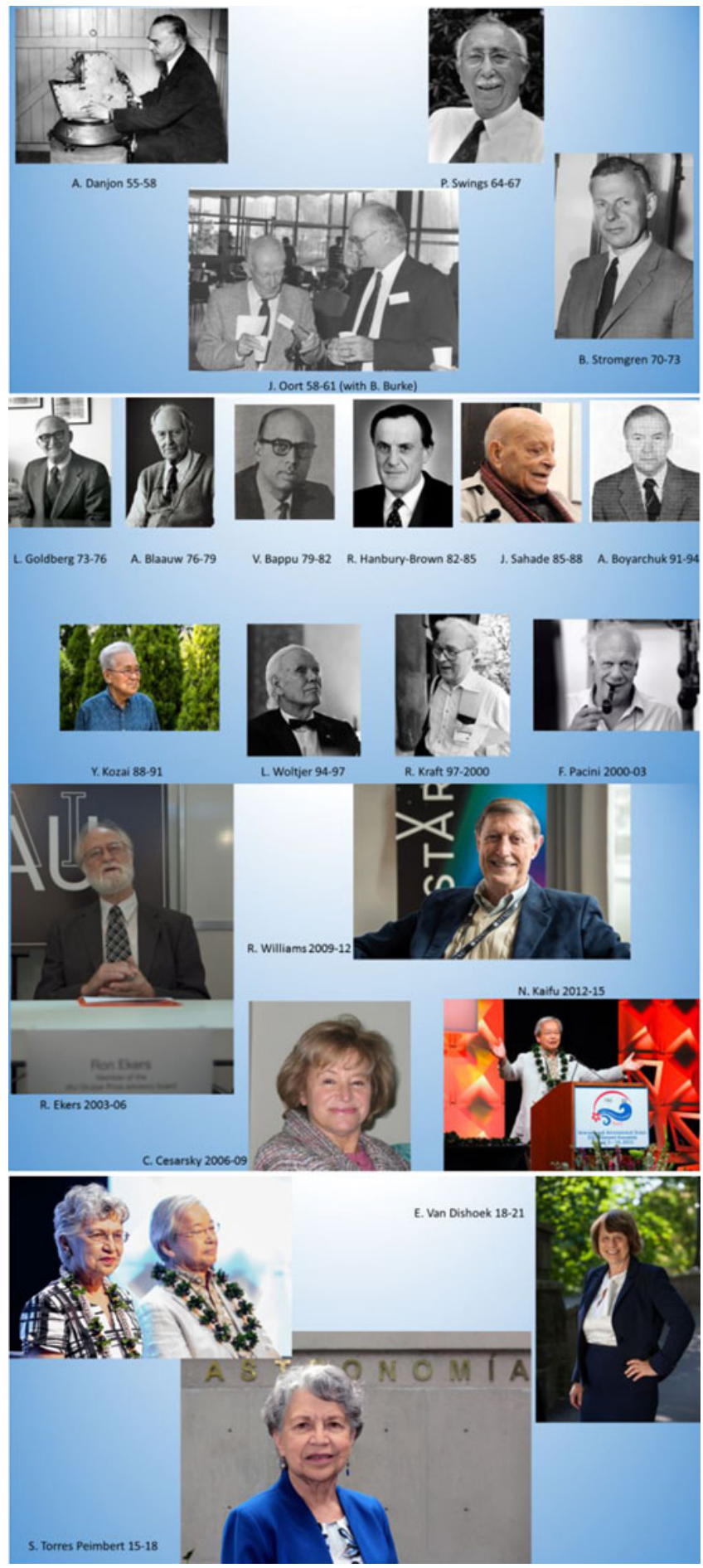

Figure 37. IAU Presidents since 1955. 


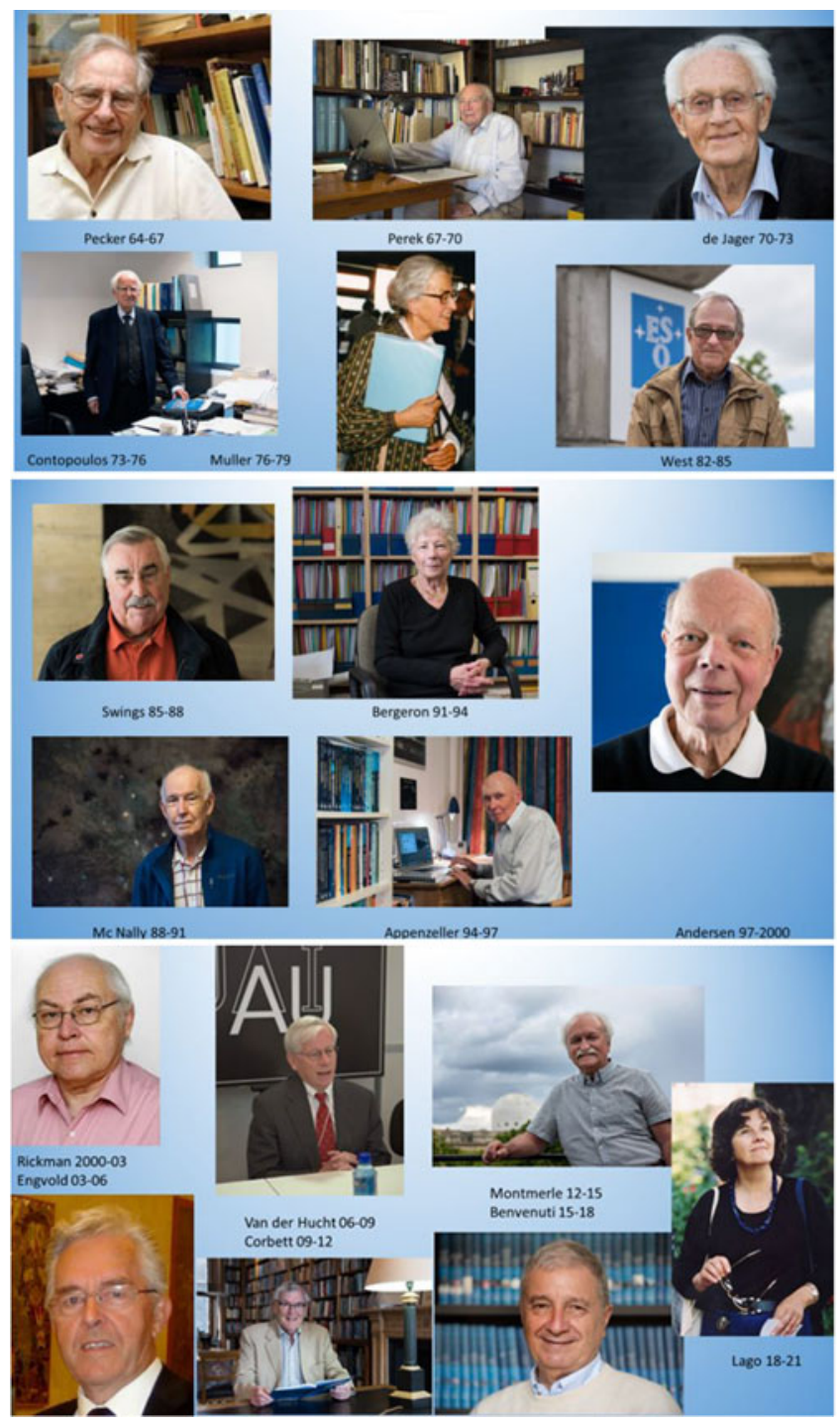

Figure 38. IAU General Secretaries since 1964.

\section{Acknowledgements}

I thank Claus Madsen, who provided me with the Chronology for IAU Member Countries and several of the photographs I used, Kevin Govender also for several of the figures, Sze-leung Cheung for discussions, Norio Kaifu for information on the Tokyo GA, and Lars Lindberg Christensen for help on various aspects.

\section{References}

Andersen, J., Baneke, D. \& Madsen, C. 2019, The International Astronomical Union - Uniting the community for 100 Years (Berlin: Springer Verlag)

Blaauw, A. 1994, History of the IAU, The Birth and First Half-Century of the IAU (Dordrecht: Kluwer)

Christensen, L. L. 2007, The Pluto Affair: When Professionals Talk to Professionals with the Public Watching, in Proceedings from Future Professional Communication in Astronomy, 
Colloquium held at the Palace of the Academies, 19-13 June, 2007. Edited by André Heck and Léo Houziaux. Bruxelles: Académie Royale de Belgique, 2007, pp. 221

Harwit, M. 1981, Cosmic Discovery - The Search Scope and Heritage of Astronomy (New York: Basic Books)

Miley, G. 2012, Astronomy for Development, Building from the IYA2009: Strategic Plan 2010-2020 with 2012 update on implementation Retrieved from http://iau.org/static/ education/strategicplan_2010-2020.pdf, International Astronomical Union

Russo, P. \& Christensen, L. L. (eds.) 2010, International Year of Astronomy 2009 - Final Report Retrieved from http://www.astronomy2009.org/resources/documents/detail/iya2009_ final_report

Russo P., Christensen, L. L. \& Cesarsky. C. 2014, The International Year Of Astronomy as a Massive Science Communication Initiative, Journal of Science Communication

UNESCO, 2005, Proclamation of 2009 as the United Nations International Year of Astronomy. Retrieved from http://unesdoc.unesco.org/images/0014/001413/141314e.pdf

United Nations, 2007, Resolution adopted by the General Assembly on 19 December 2007. Retrieved from http://www.un.org/en/ga/search/view_doc.asp?symbol=A/RES/62/200\& Lang $=\mathrm{E}$ 